\title{
A QUESTÃO DA REPRESENTAC̄̃̃O POLÍTICA NA PRIMEIRA REPÚBLICA
}

\author{
Cristima BuarquedeHdlanda*
}

\section{APRESENTAÇÃO}

A narrativa usual a respeito da Primeira Re pública brasileira funda-se na idéia de ausência. Trata-sedeum tempo queocupa olugar do equívoco na memória do país. Não obstanteo desacordo sobreos futuros possíveis para a Nação, entreaprimeira geração de homens públicos da República havia notável convergênciano diagnóstico dacena política observada: experimentava-se no Brasil a antítese da República; o avesso da ordem anunciadapelapropagandarepublicana. Seahistoriografia abriga raros consensos, a falência deste ensaio da República- ou a profundainadequação aseusprincípios defundação - tende a ser um deles.

Incontáveis episódios detormento social e instabilidadepolíticamarcaram, defato, os primeiros anos da República. As tensões em torno da reconfiguração dos poderes implicaram duras e

* Doutora em Ciência Política pelo IUPERJ. Professora do Departamento de Ciência Política da UFRJ, colaboradora do Programa de Pós-Graduação em Ciência Política da Universidade Federal Fluminense.

Largo de São Francisco, n. 1. Centro - Rio de Janeiro Brasil. cbuarque@iuperj.br instáveis negociações entreas oligarquias locai se os governos estaduai s efederal. Embora o federalismo daCarta de 1891 estivesseperfeitamenteafinado coma demandaeo modo devida federalistas dasociedaderecémingressana República(Souza, 1969), a definição de novos padrões e personagens desustentação política não constituiu tarefa trivial. À diferença da relativa unidade imperial em torno da figura do Rei, a República trazia as marcas da dispersão política eda desordem social. Destaindeterminação original resultou a grave instabilidade das origens republicanas no país.

Foi o arranjo institucional deCamposSales que instituiu rotina política na República (Lessa, 1999) e retirou-a da órbita da absoluta imprevisibilidade. Para o político paulista, um "parlamento com substância liberal, formado a partir deescol has individuais dos cidadãos esegmentado segundo as clássicas divisões políticopartidárias" (p.6) seria incompatível com os propósitos de consol idação do regi me republicano. Os parâmetros formai s da Constituição eram, afinal, incapazes deorganizar o cotidiano real da vida pública. A principal motivação política de Cam- 
pos Sales foi, portanto, a deopor um princípio de vertebração social a este ambiente desordenado. As instituições do liberalismo político constituíam, nesta perspectiva, um obstácul o ao andamento desejável da vida pública.

O modelo de representação política que estruturou a cena republ icana original baseou-se, portanto, num fundamento claramenteanti-liberal, avesso ao sistema partidário eaos demais instrumentos da democracia representativa liberal. Nesta matriz política, o objeto da representação eram as uni dades federativas, e não o indivíduo ou o povo. Segundo Renato Lessa, o sistema de Campos Sales teria reeditado a prescrição mandeviliana dos vícios privados e virtudes públicas para a formulação oligárquica do particularismo estadual e da unidade nacional (Lessa, 1999, p.6). O ajuste el eitoral baseado nos estados resultaria na constituição de um corpo nacional único e ordenado. Este seria o caminho da conversão do particular em universal .

O protagonismo dos estados não era, contudo, auto-suficiente. As ol igarquias locais foram elementos centrais na configuração da simbiose política que perdurou, a despeito de importantes contratempos, por toda a Primeira República. A praxe política inventada por Campos Sales visava contornar a excessiva carga contenciosa dos governos da primei ra década republicana. No seu modelo político, o presidenteda República concedia apoi o irrestrito aos estados em troca da garantia, por parte dos governadores, de bancadas legislativas afinadas com suas diretrizes. A ação política dos presidentes deestado fundava-se, por sua vez, num model o dereciprocidadecomasoligarquias. Os coronéis, importantes operadores destemodelo político, zelavam pela fidelidadedas eleições ao resul tado esperado pel os governos estadual efederal. Em troca disto, faziam-se verda deiros soberanos locais.

Esta delicada arquitetura de personagens políticosfundava-se na adulteração decada uma das etapas do processo de constituição de poderes - isto é, alistamento, votação, contagem dos votos everificação final dos diplomas, entregueao próprio Poder Legisl ativo na figura das comissões deverificação de poderes do Congresso. Cada plèto oferecia ao país um espetáculo decomédia elejtoral, conformeexpressão da época. Os mandatos de deputados, senadores e governadores de estado eram sabidamente produto de arranjos políticosinformais.

O sacrifício dos princípi os el ementares da representação liberal era, portanto, o custo da previsibilidadena política. A condição da relativa estabilidadeinstituída por Campos Sal es era a garantia da fraudenos processos formais de produção da política. A despeito do novo equilíbrio de poderes, a República não provocara, portanto, em matéria el eitoral, rompimento substantivo comas rotinas do Império. Os rituais da representação política permaneciam inscritos num universo ficcional fundado no divórcio entrenormas eprá ticas da política.

É fundamental notar, contudo, que, a despeito do inequívoco predomínio político do model o Campos Sales durantea Primeira República, a refl exão sobre representação política não serestringiu a seus limites. Liberais, positivistas e realistas representam três importantes matrizes da crítica aos caminhos reais da política. A compreensão sobre o tema da representação na Primeira República não pode passar ao largo de um olhar mais detido sobreessas tradições do pensamento político brasileiro. O objetivo desteartigo éjustamenteo deinvestigar as reflexões liberal, positivista e real ista sobre representação política- caracterizadas, a despeito das distâncias importantesentre si, pela recusa do modelo dealternância depoderes. Dito deoutro modo, trata-sedeenxergar otema da representação política na Primeira República pela marca das presenças, enão pelaimagem habitual da ausência.

\section{LIBERAIS, POSITIVISTAS, REALISTAS E A QUESTÃO DA REPRESENTAÇÃO POLÍTICA}

A insatisfação deliberais, positivistaserealistas coma relação simbiótica eextra-formal entre 
estados e oligarquias, embora devida a motivos diversos, convergia no reconhecimento do povo como inspiração necessária da representação política. Seja como operadores e/ ou meros receptores da política, os men in the street, conformeexpressão de Azevedo Amaral, eram descritos como eixo fundamental da política. Asimportantes distâncias entreosmodos deinterpretar a realidadesocial não tinhamnenhumarelação, portanto, comoaceite ou a recusa dos sujeitos ordinários como objeto da ação política, mas com as diferentes concepções sobreo que fazer de uma real idadesocial profundamentefragmentada edispersa.

Antes, contudo, deavançar no tratamento das diferenças normativas, vale ai nda reforçar os pontos deafinidadeentreas três principai smatrizes dereflexão sobre o problema da representação política na Primeira República. Havia umacordo largo em torno da existência de uma política frágil eincipientecomo conseqüência necessária da deficiência sociológicacrônica observada. Nestaperspectiva, o ambiente povoado por átomos desordenados não era ti do como favorável à consol idação do interesse público, por definição, inteiro e indivisível. Os críticos de Campos Sales não lidavam, portanto, com o problema da representação política em abstrato, mas em alusão à re alidade concreta na qual se inscrevia. Era o tema da amorfia popular que moldava, enfim, o ol har dos políticos para o desafio da representação.

Além desta importante afinidade no diagnóstico da realidade social, a especulação sobreas causas deste cenário também aproximava os insa tisfeitos com a rotina política original da República. Emlinhas gerais, acordava-sequea sociologia fragmentadatinha origem extrínseca aos indivíduos que padeciam da dispersão. Vítimas de uma ordem política profundamente excludente e autárquica, as massas não eram tidas como sujeito de seu próprio infortúnio. Mesmo entre os liberais, que concebem patamares mínimos de ação do governo, o rompimento com essa situação indesejável não era esperado dos cidadãos comuns, mas dos homens públicos e do Estado.

Em fragmento dediscurso pronunciado por
Irineu Machado no Senado, esta perspectiva é enunciada de modo claro: "Todos os povos são feitos da mesma massa, énecessário quemãos va Iorosas venham plasmar o organismo deuma $\mathrm{Na}$ ção, tirando-a dos caos da sua origem." (Anais Senado, 1921, p.558) Longe de legar aos homens desordenados a responsabilidade por sua desordem, o senador identifica nos usos inoportunos da política o foco da grave dissipação social .

Diantedo déficit educacional do povo, os sujeitosilustrados pel o privilégiodaculturateriamuma missão social a desempenhar. A falha em atender a estadesignação marcariaatrajetória equívoca dedeputados esenadores apartados do ideal republica no. Nesta perspectiva, os principais operadores do Estado eram tidos como perpetuadores das condições de desventura das massas, inaptas a redefinir, por si sós, os seus caminhos. Nomesmo discurso, o senador contrastaaimpotênciado povo deseducado coma potênciadoshomensilustrados:

O povo brasileiro é um povo que ainda não está educado, conscientemente de seus deveres, e, neste caso, àqueles dos mais cultos e felizes a quem Deus concedeu a fortuna de poder desenvolver a sua inteligência e a sua cultura, a esses cabe o sagrado dever de coração de pôr a sua alma ao serviço dos mais desventurados nesse profuso amor, neste sentimento de bondade, de altruísmo que é uma forma da perfeição humana, do dever patriótico (Anais Senado, 1921, p.562).

Destediagnóstico das capacidades diferenciadas Irineu Machado deriva graveacusação aos colegas del egislatura:

Vós outros não tendes a coragem, vós outros, que tendes diante de vós a força que a natureza vos deu, multiplicadas pelo vigor da inteligência, pela fortuna, pelas aspiracões da glória, em vez de serdes os servidores da Nação, sois os seus traidores, deixando-a mergulhada nessa vida infecta de humilhações, de servilismo e de subserviência. Não foi essa a promessa exarada no tribunal da consciência publica, jurada no altar da rel igião republicana, que os apóstol os da de mocraciafizeram. Não! Não foi essa, eles mentiram (1921, p.562).

À definição clara de al gozes e vítimas do infortúnio social corresponde igual nitidez a respeito do lugar e do modo de superar o equívoco 
da vida política. Seo povo não estava inteiramente isento de responsabilidades sobreseu destino, sem dúvida ocupava um papel coadjuvantediante da potência demetamorfosesocial identificada no Estado.

As distintas reações normativas ao diagnóstico de uma massa amorfa eimpotentediantedas causas deseu infortúni o convergem num duplo e necessário fundamento político do governo, o de criação eunidade do povo. Esta inscrição comum tem importanteafini dade com a dotação política do soberano de Hobbes, dotado da facul dade de invenção do sujeito representado (Jaume, 1986). $\mathrm{Na}$ teoria hobbesiana, os homens padecem dos males da desordem quando dispersos numa multidão destituída de forma, que precede o próprio conceito de povo. Na fábula política daqueleautor, o medo da morteviolenta só ésuprimido quando, através do uso da razão, os indi víduos constituem-senum pacto esubmetem-secol etivamente aum poder deenormes proporções (Hobbes, 1989). A conversão da dissi pação em unidadeéo principal movimento da passagem fundamental do caos originário à civilização. Há de se notar, contudo, nesta formulação hobbesiana, um importanteparadoxo: os homens dispersos queinstituem o pacto não constituem o objeto da representação na nova ordem. Estes indivíduos são reinventados pel o soberano eesta éa condição da sua existência como um coletivo ordenado. A ação representativa é dotada, portanto, de uma vocação criativa, voltada sobretudo para a unificação das células isoladas na idéia comum de povo. A possibilidade da ordem política, preocupação fundamental de Hobbes, reside, portanto, na supressão das partes ena constituição de um todo indistinto.

Longe de confinadaà tradição política autoritária, como poderia sugerir a anal ogia com a teoria hobbesiana, a suposi ção de uma natureza criativadorepresentanteesteveclaramentepresente nateoria política de dois importantes símbolos do liberalismo brasileiro na Primeira República: Rui Barbosa eAssis Brasil. Para ambos, as rotinas formais da política não configuravam mero procedimento, mas a possi bilidadedeo Estado conduzir umvalioso experimento de pedagogia política. As semel hanças entreas matrizes interpretativas destacadas detém-se, portanto, no plano dos diagnósticos e não avançam nas formulações positivas sobre como a sociedadee a pol ítica devem ser. As normas abrigamas diferenças, emboraigual mente inscritas na suposição comum da política como lugar decriação.

\section{Rui Barbosa e Assis Brasil: origens do libera- lismo republicano}

Legado à história como o principal íconeda tradição liberal no Brasil, Rui Barbosatambémacumulou o estigma deum intelectual divorciado da realidadedo país. Emsintonia com a reflexão liberal de gestação estrangeira, Rui Barbosa passaria ao largo das idiossincrasias nacionais.

Dos discursos pronunciados na Campanha Civilista, de1909, ena campanha pelo governo da Bahia, de 1919, depreende-se, contudo, umaclara preocupação do político com as particularidades denossa formação social. À diferença do clássico discursoliberal, que definea ação estatal em patamares mínimos, Rui Barbosa evoca o Estado e os homens públicos como importantes personagens da vida política. O despreparo cívico do povo é ti do como resultado da negl igência dos governos. Segundo ele,

Se os nossos homens públicos amassem o seu contacto, e lhe cultivassem a companhia [referência ao povo], (...) a nossa nacionalidade teria desenvolvido os costumes do governo representativo, o povo não se retrairia, como se retrai, ao trato dos homens deEstado, eas agi tações políticas, tão ordinárias eessenciais nas democracias, não dariam ensejo, aqui, aos maus governos e seus sequazes, de as criminarem como obra de conspiradores, ou manejo de revolucionários (Barbosa, 1967, p.51).

A idéia do povo como objeto de uma classe política vilanizada perpassaseus discursos decampanhana Bahia, nos moldes do fragmento a seguir:

A política, entendida como a ciência de governar bem os homens, as devia acendrar e mel horar [referência às qualidades dos homens], gui- 
ando-lhes a educação e a cul tura. Bem fora daí, porém, a política, em cujas mãos caiu o sertão baiano, é a que tem por objeto estimular, no homem, os instintos subalternos, asselvajá-lo e animalizá-lo (p.98).

Nesta perspectiva, a política é tida como instrumento passível de bons e maus usos. $\mathrm{Na}$ cena política observada, não restariam dúvidas quanto à impertinência das ações dos homens de Estado. Os sertanejos, personagens a quese di rige a campanha política de Rui Barbosa, estariamcondenados a uma "vida estagnadae coagulada" (Barbosa, 1967, p.36), a uma existência marcada pel o imperativo da sobrevivência e aprisionada pelas exigências materiais imediatas, fato incompatível com as demandas da vida pública. A causa deste infortúnio eraclaramentepolítica.

Para Rui Barbosa, a distinção fundamental entresertanejos elitorâneos era apenas devida ao acaso, relativa ao abismo entre seus respectivos ambientes desocialização. Os processos degrave espol iação queseabateram sobrea população do sertãoter-Ihe-iamextinto todo vigor cívico. $O$ acento na idéia deuma "raçainteligente, degrandevital idade", investida de um "brônzeo heroísmo", localizava a responsabilidade pel os desacertos políticos nos al gozes do povo desfrutado. Eram as classes políticas locais, extremamenteoportunistas, os sujei tos por excelência da degradação do sertanejo. O fato da profunda desagregação cívica tinha, portanto, uma geneal ogia social muito evidente.

Nesta perspectiva, o povo, a despeito desua existênciadesordenadaeamorfa, não constituía um obstáculo ao aprimoramento da vida pública. O Estado, os homens públicoseo próprio ritual eleitoral acumulavamapossi bilidadedesuperação deste graveproblema dadispersão. A correção dos meios de constituição dos poderes, por si só, não seria capaz deconduzir essatransformação. A expectativa de metamorfose cívica, embora não anulassea ação política do povo, não selimitavaà expectativa deum espontaneísmo qualificado dos homens comuns, isto é, de um espontanéśsmo incrementado pelacorreção dos procedimentos eleitorais.

Se o voto era tido por Rui Barbosa como direito inalienável dos indivíduos, suateoria polí- tica não prescindia de um movimento quese projetasse decima para baixo, moldando a cena dissipada conforme a índole unitarista do interesse público. Nesta perspectiva, o povo eratido, simultaneamente, como sujei to eobjeto da criação política. Isto é, a condição desua identi dade ativa seriajustamentea intervenção modeladora do Estado ou dos personagens da vida pública, destinada à garantia dal isura dos processos el eitorais etambém a uma certa pedagogia cívica. Não fosseainterferência deumator externo, a massa desagregada segui ria entregue às condições de reprodução de seu infortúnio. Não haveria propósito em crer que, deixados asi mesmos, como estavam desdesempre, os homens comuns iriam organizar-se por si sós e, deste modo, configurar, à sua imagem esemel hança, uma Nação ilustrada pela boa política. Todo mimetismo da política com a sociedadeestava fadado à reprodução do atraso. A perspectiva mais verossímil, se abolida uma ação incisiva e renovadora por parte do Estado, era, portanto, a deperpetuação do desalento. Considerada a grave apatia política do povo, a cena política não poderia configurar-secomo espel ho da real i dade social, típica metáfora liberal. Se não havia um povo claramenteconstituído, não haviaa possi bilidade de a representação política si mplesmente reproduzir uma cena social já existente.

A possibilidade de rompimento com esta inércia degenerativa estaria localizada, portanto e sobretudo, no campo estatal. Ao imprimir movimento a um universo estagnado, o Estado poderia ativar um círcul o virtuoso, em substituição ao círculo vicioso perpetuador das condições do atraso. No discursoliberal em evidência, os recursos formais da política são investidos de notável força transformadora ou, ao menos, originadora datransformação.

Esta leitura da pol ítica não está confinada ao liberalismo ruiano. $\mathrm{O}$ argumento de Rui Barbosa tem clara afinidade com a teoria política deAssis Brasil, outra personagem do liberal ismo naPrimeira Repúbl ica com importanteprojeção na cena política do Rio Grande do Sul. Assis Brasil manifestafortecrençana capacidadedeos meios políti- 
cos modificarem e moldarem a índole do povo conformeo imperativo da vida cívica. O lugar da política é definido em franca sintonia com a pre missa progressi va ecumulativa da pedagogia. Tal como o aprendizado do andar, quando "a criança hesita, cai epor vezes quebraatéo narizinho" (AssisBrasil, 1934), o exercício político implicatentativas eerros sucessi vos atéo al cance de uma situação mais estável edificilmentesuscetível à queda. Embora Assis Brasil não identifique, como Rui Barbosa, uma natureza heróica no brasileiro, tampouco deriva qual quer sortedefatal ismo político da observação da real idade social .

Para Assis Brasil, portanto, a experimentação éa condição do aperfeiçoamento; o acerto político é o corolário dos desacertos. Ainda que o mau governo seja o destino inexorável doshomens queempreendem o voto desqualificado, éa exposição a esteinfortúnio que abriga a possi bilidade deconversão moral dos eleitores eseus governos. Essa perspectiva deuma pedagogia el eitoral destinada ao melhoramento da vida pública estáclara no seguintefragmento dediscurso:

A nação também se corrige, tem também as suas neuroses, os seus momentos, suashesitações, seus emportements, mas é preciso deixar queela viva, segundo deva viver. O caso da nação éo mesmo decada um denós: (...) na água éque seaprende a nadar. É no exercício da função queo indivíduo adquire idoneidade para essa mesma função. É, pois, preciso que a nação tenha liberdade, não como querem os nefel ibatas e sonhadores, para fazer os seus governos de anjos. Quero quea nação tenha li berdade para fazer os seus maus governos, porque é pelo preço de fazer os maus negócios ede dar os maus passos que os homens eos povos aprendem a dar bons ea ser dignos de sua liberdade. A representação ver-dadeiraéuma necessidade; não para fazer bom governo, mas para tornar o povo apto a fazer um bom governo (Assis Brasil, 1933).

Para o político gaúcho, a qualidade do governo evoluirá, portanto, na medida da prática elejtoral, desde que garantidas as condi ções corretas parasua execução. Assim como em Rui Barbosa, e deum modo ainda mais contundente, os procedimentos e o conteúdo da política são percebidos por Assis Brasil como um contínuo. Nesta perspectiva, não hárompimento entrea forma easubs- tânciadapolítica. Istoé, a garantia daformaincide demodo determinantena produção dasubstância política evice-versa. Emboranão destituído detensões, o laço estreito entreformae conteúdo ilustra a crença do liberal ismo brasileiro na potência criativada política, enão meramentena suacapacidade de reproduzir, como uma imagem especular, uma real idade já constituída. Isto é, o universo formal étido, nesta tradição depensamento, como instrumento para a metamorfose dos usos e hábitos políticos.

À semelhança da formulação política de Hobbes, portanto, a percepção do li beralismo republicano original era a de que o povo não pré existiaao momento da representação. À diferença, contudo, do extremo hobbesiano desupressão dos direitos políticos, osufrágio universal eratido como uma realidadeda qual não era possível retroceder. Sendo um dos imperativos da vida moderna, restava aos políticos a educação deste meio. Nesta versão mitigada do princípio hobbesiano de representação, a quali ificação política dos cidadãos teria um dupl o fundamento: a ação do representanteinstituído e o próprio processo deconstituição de poderes.

Nesta perspectiva, a transi ção da massa ao povo - isto é, do agl omerado desordenado ao conjunto ordenado de almas populares - resultaria da intervenção criativa do Estado e também das incursões diretas dos el ei tores ai nda não qualificados à vida pública. Os homens comuns seriam, a um só tempo, produtores eproduto darepresentação política. Estemodelo híbrido, a despeito das concessões aos fundamentos do li beral ismo clássico, guarda importantesemel hança coma matriz hobbesiana deunidadee criação do povo. A concepção derepresentação política na Primeira República brasileira, a despeito das nuances queparticularizam seus diferentes matizes, estáclaramente pautada, portanto, numa dupla expectativa de iniciativa política doscidadãos eação model adora do Estado. 


\section{O positivismo e a representação política como substância}

Se a premissa do Estado como móvel essencial davidapública constitui marco importante do pensamento liberal nas origens da República, foi no castilhismo queeste fundamento al cançou expressão máxima. Nesta filosofia política, baseada no positivismo deAugusto Comte, o princípio deimpotência do povo élevado aolimite. A constituição estadual do Rio Grandedo Sul, de14 dejul ho de 1891, subordina toda ação legislativa ao corpo executivo, num claro rompimento como fundamento liberal daCartaConstitucional do país. Para Assis Brasil, um dos críticos mais contundentes do castilhismo, no estado gaúcho "a Lei Fundamental confereexclusivamenteao déspota a faculdade de fazer as leis, de as regulamentar e aplicar, pondo-Ihe apenas na mandíbula pantagruélicauns freios irrisórios demanteiga, que ele traga e digere" (Assis Brasil, 1925). Nesta ordem política, o soberano goza, portanto, de larga concessão de poderes.

A precedência daciênciasobreoutros crité rios de organização da vida social é a principal marca desta matriz deentendimento da representação política. Longe dafortuna incerta das opiniões, queconfigurama política no paradigmaliberal clássi co, a cena públ ica apurada pel o saber científico não estaria fadada aos caprichos da forma, mas animada pel a atribuição de substância oportuna, queinstitui estabilidadee permanência na política.

Nesta perspectiva, o entendimento da re presentação política estámenos referidoà mi núcia dos mecanismos eleitorais do queao princípio do bem público, quenão está disponível às consciências ordinárias e depende de um exercício criativo, e não mimético, da representação por uma minoria esclarecida. Técnica, ciência, competênciaesaber constituem, enfim, o campo semântico da idéia derepresentação no marco positivista.

Embora prescindado conceito de democracia- ou faça a el econcessões meramenteformais, a representação positivista identifica no povo a motivação primordial da ação política. Sem referência aos homens comuns, a moral e a ciência constituem meios desprovidos definalidade, corpos carentes deal ma. A técnica eo imperativo de pureza dos espíritos, temas positivistas por excelência, não sejustificam por si mesmos, mas pela convicção de que conduzem a sociedade ao bem comum e, portanto, de que a representam. Se o argumento do saber conduz à definição de uma minoria privilegiada pel o conhecimento, não defineuma mai oriaindigna derepresentação. A vontade do povo, inacessível asi próprio, éinterpretada pelo governante, dotado da faculdade e da oportunidade do conhecimento. À semel hança do Grande Legislador rousseauniano, o chefe político éuma figura excepcional capaz de conhecer a consciência oculta que é de todos e de cada um, sem ser da maioria ou da minoria dos homens. Os sujeitos ordinários edesconhecedores desua própria vontadesão descritos, nesta perspectiva, como objeto - enão sujeito - da representação.

Para Borges de Medeiros, principal operador do castilhismo, todos os homens produzem desejo na medida em que experimentam a necessidade, mas poucos são capazes de refletir adequadamentesobreesta condição comumeascender à produção de saber. Sendo o desejo uma pulsão el ementar, própria de uma "organização cerebral aindarudimentar" (Medeiros, 1933, p.47), a experiência da opinião, queimplica pensamento econhecimento analítico, ocupalugar superior e acessível apoucos.

O reconhecimento da opinião como faculdade restritiva sugere a existência de um sujeito cognoscente privilegiado, descolado do reino da escassez imediata eilustrado pelo exercício da razão, em rígi do contraponto aos homens escravizados pelas restrições do mundo material evulnerá veis à imprevisibilidade dos desejos. No texto da plataforma do positivismoilustrado, lê-se: "quanto aos meios deatingir o fim, competeexclusivamente aos sábios em política escolhêlos. Seria absurdo queamassaquisesseraciocinar." (Paim, 1981b, p.49) O uso do termo massano lugar depovo não écasual. Tal como em Hobbes, refere-se a um coletivo 
amorfo, desprovido deidentidadeeincapaz, portanto, deexprimir uma opinião acabada.

Na política desprovida deciência econsa grada pelo uso ordinário reside, enfim, a dissi pação, o estorvo das facções, a dominância das partes em detrimento do todo. As rotinas el eitorais da Primeira República, marcadas pela fraude, eram tidas como sinal da decadência e imperativo da mudança. O espetáculo periódico dos pleitos eleitorais revelaria o avesso do mundo desejado, a profusão dos interesses particularistas em lugar deações inspiradas pelo bem comum.

A crítica contundente à rotina política da República assentava-se, portanto, numa visão sobrea representação políticaradical menteal heiaaos parâmetros dacarta de 1891. O rigoroso centralismo castilhista buscava contornar o equívoco da habilitação política direta do povo, deslocando o homem ordinário de sujeito para objeto da política. À diferença da perspectiva liberal, queconcebia o povo como autor eator da política, o positivismo brasilei ro não previa uma duplicidade de papéis para o indi víduos comuns. A ação do Estado, de votada ao bem público, deveriaser incontrastável, única hipótese compatível com a expectativa de verdade da representação.

\section{O realismo e a representação política como farsa}

Emboraconstitutivodavisãosobrerepresentação política deliberais epositivistas, o desencanto coma República foi expresso demodo maiscontundentepor autores realistas como Oliveira Viana e Alberto Torres, dedicados à crítica do desajuste entrenormaeprática política. Para eles, o realismo sociológico é condição elementar da arquitetura política; o mundofenomênico éaúnicainspiração possível paraa política. Nostermos deAlberto Torres, "o senso nacional não pode ser idêntico para todos os povos. O nosso país precisa, de uma vez por todas, formar um espírito euma diretriz prática, que o conduza" (Torres, 1938, p.46). O encanto com "paradigmas forasteiros" seria um grave mal denossa constituição política.
Nesta perspectiva, o reconhecimento da própria al ma libertaria o povo das angústias que não eramas suas, mas quecolonizavamsuaidentidade política. Não cabia a nós a agonia dos povos desordenados pela ruína de instituições seculares e pelos descaminhos do liberal ismo. Era outra a natureza de nossos problemas, ainda obscuros e carentes deinvestigação. Nesteambiente, graveprejuízo causavaa "influência mental da França”, que nos fazia repetir, "por símbol os da nossa psicose" (p.76-77), um repertório al heio depreocupações.

Imbuído nestamesmaleitura, OliveiraViana Iamenta: "nenhum dos nossos constitucional istas havia procurado cunhar as leisemmetal brasileiro, dentro dos moldes das nossas conveniênciasnacionais" (Viana, 1930, p.22). Do abismo entre realidade e legal idade resultava a impossi bilidade de uma organização pol ítica "viva eorgânica, feita de músculos, nervos esangue." (p.17) Nossa existência social, sem ossatura e sustentação, al icerçada em rudimentar "patriotismo tribal", não guardava semel hança com as virtudes cívicas de além-mar. Era preciso mol dar a política deacordo com as características particulares denosso ambientesocial.

Nestaperspectiva, a sociologia eratida como poderoso determinantedapolítica. A abstração das normas, na visão real ista, não era um instrumento favorável à alteração da realidade. Para Oliveira Viana, haveriagraveequívoco em conceber a"forçalógica do raciocínio e da dialética como agentes determi nantes da conduta de multidões" (p.129). Todo intuito normativo era estéril quando al heio ao contexto específico quepretendemodificar.

O profundo sentimento deinadequação era expresso, entre outros modos, por fortenostal gia do Império. Feita contraponto prático emoral ao decadentismo republicano, a política imperial era descrita como ação retificadora. A alusão saudosa ao Poder Moderador valorizava sua potência de harmonização de uma cena social dispersa e excessivamentefragmentada. Nadana República assemelhava-sea estenotável engenho deorganização da vida pública: "nossos costumes de facciosismo epoliticagem" (Viana, 1930, p.43) seguiam curso livre, sem impedimentos dequal quer 
ordem. Fal tava um Estado forte que ordenasse os vícios particularistas eoperasse como "poderoso modificador sociológico" (p.48).

Além da crítica ao federalismo da Carta de 1891, OliveiraViana critica, na República, ostempos curtos dos mandatos políticos e as eleições dos poderes Executivo e Legislativo. Aí estariam as origens da instabilidade e dos maus usos da política (Viana, 1930, p.27). O desejo deorganização da vida pública, bem como a gestação de um "grande ideal coletivo" (p.314), dequeainda não dispúnhamos, são formulados em outras bases:

Esseal to sentimento e essa clara e perfeita consciência só serão real izados pel a ação lenta e continua do Estado - um Estado soberano, incontrastável, central izado, unitário, capaz de impor-se a todo o país pelo prestigio fascinante de uma grande missão nacional (p.315).

Alberto Torres foi o precursor, entre os realistas, desta alusão ao Estado como fio condutor da política. Para ele, a principal carêncianacional era de "um governo conscienteeforte, seguro dos seus fins, dono da sua vontade, enérgico e sem contraste". Em oposição à excentrici dadeliberal, Torres concebia o chamado Poder Coordenador como protagonista da harmonia social. A peculiaridade deste poder era seu caráter vitalício. Sua permanência constituiria valioso contraponto à nocivainstabilidadeda ordem republicana, flutuanteao sabor do desvio faccioso da política. Tratava-se de opor o permanente ao transitório, com vistas à estabilidadee unidade da vida pública.

O problemacentral do revisionismo real ista era, portanto, o de instituir "um quarto poder, tal como o antigo poder moderador, que, sendo judiciário, tambémtenhao direito deiniciativa." (Viana, 1930, p.48) A determinação deumcentro deforças quesubmetessetodas as células do governo constituía o contraponto necessário de uma "sociedade sem fixidez, sem ossatura declasses" (p.92).

Diantedo fato incontornável denosso atra so sociológico, o exercício forte da política configurava-se como imperativo social. Para Oliveira Vianna: "os povos de fraco sentimento coletivo, isto é, aquel es em quea consciência do grupo na- cional é rudimentar ou nula, não podem el evarse, por si mesmos, ao culto do Estado e da sua autoridade." (Viana, 1930, p.100) Desta incapacidadedesuperação espontânea o autor deriva forte associação entre princípio deEstado ereal ismo:

O Brasil precisa realizar desde já uma al ta política de caráter profundamente orgâni co e nacional. Esta política, porém, só pode ser feita por iniciativa do Estado. Ora, o Estado, pel a maneira por queestá organizado na Constituição vigente, não pode eficazmente real izá-la. Logo, tudo de pende de uma reforma constitucional que organize o Estado num sentido que o capacite para este fim superior e necessário (p.13).

Diantedeumasociologiaextremamentefrá gil e, ao mesmo tempo, poderosa para definir os rumos da política, o Estado concebi do por Oliveira Viana é descrito por sua capacidade de sobrepor-se ao fato da profunda desagregação social . Contra a potência de desordem implicada nas massas, deve-seopor uma força incontrastável. À diferença do liberalismo de Rui Barbosa e Assis Brasil, a condução da vida pública, na perspectiva realista, éclaramenteincompatível com concessões à expressão política das massas. A habi litação política de indivíduos inábeis configura o próprio avesso do princípio de representação, que supõe a figura metonímica da partepelo todo. Asmassas desqualificadas não estão em condições de, efetivamente, projetar-se na vida pública e indicar os bons caminhos. O ceticismo real ista com rel ação às possibilidades de a política configurar o mundo social não é formulado indistintamente, mas em relação aos usos observáveis da política.

No real ismo, portanto, não há propriamente uma concepção de representação política, mas deação política. Isto é, sea representação supõea projeção virtual das massas ignorantesna configuração da política, deveser abolida como categoria razoável deintervenção na vida social. Mais acertado éconceber uma ação política estrito senso, que se projeta na cena social para moldar o desastre sociológico. Toda concepção contrária, quesupõea relação inversa de produção da política pelo povo, étida como fal sa e estéril para pensar, realmente, qual quer tipo demetamorfosesocial possível. 


\section{CONSIDERAÇÕES FINAIS}

Embora a formulação real ista seja expressão limi te da premissa de inabilidade política do povo, o suposto basilar do Estado como agente de modelação da sociologia tevenotável permanência nos diversos entendimentos sobre representação política na Primeira República. Mesmo o pensamento liberal das primeiras décadas republicanas afasta-se do princípio da representação como processo destituído de conteúdo finalístico e afeito unicamenteà expressão devontades pré-constituídas. A versãoliberal brasileira imprimiu unidade esubstância ao problema representativo. A habilitação cívica do povo não dispensou a ação política marcadamenteestatal.

A figura de um soberano resoluto, capaz de imprimir di reção àvida pública, não esteve confinada, portanto, aos marcos do positivismo. Sendo criador ecriatura da política, o povo era dotado deumaidentidadehíbrida, moldadaem simbiose com a política sediada no Estado. A ação política dos homens comuns não era absolutizada e tampouco suprimível da cena pública.

O Código El eitoral de 1932, marco jurídico deencerramento daPrimeira Repúblicano quediz respeito ao tema da representação, expressou claramente a preocupação liberal com a garantia de bases consistentes para a ação do governo. Seu principal autor foi Assis Brasil. Nestetexto político, a formulação de um modelo el eitoral híbrido, baseado nos princípios proporcional e majoritá rio, buscou combi nar a representação das minorias com garantias à configuração de uma sólida mai oria parlamentar, compatível com as necessidades de governo. Isto é, os segmentos menores do el eitorado eram admitidos na arena congressual na medida em quenão produzissem impedimentos para o livre curso da política. Os fragmentos eram habilitados, portanto, sob a condição denão comprometeremaunidadeda política.

Além desta arquitetura el eitoral, outrasnovidadestambém merecemser notadas no primeiro código el eitoral brasileiro. A garantia do voto secreto - um avanço com rel ação ao voto simples- mente coberto - , a extensão do direito de voto às mulherese, sobretudo, a invenção dajustiça el eitoral - queretirou do Legislativo o julgamento da matéria legislativa - foram marcas inequívocas de al argamento do princípio representativo na direção do liberal ismo democrático. A preocupação em garantir condições reais para a ação substantiva de governo - sem o obstáculo excessivo das minorias e da crítica - associou-se, portanto, com conteúdos clássicos do liberal ismo, afinados coma perspectiva da representação como espel ho de uma cena política já constituída. O encerramento formal da questão representativa na Primeira República não escapou, portanto, ao hi bridismo liberal da época, queenxergava o povo, si multaneamente, como sujei to e objeto da política.

A conversão em lei desta curiosa formulação política baseou-se num paradoxo original : o fato do avanço liberal ter-seinscrito no preâmbulo deum regimepolítico autoritário. Emboranão escapassem ao campo liberal, os temas daunidadee dacriação na política foramapenas possíveis, portanto, pel o fato deestarem inscritos numa ordem quejáseanunciava autoritária.

(Recebido para publicação em janeiro de 2008) (Aceito em março de 2008)

\section{REFERÊNCIAS}

ANAIS DO SENADO, 1921 Disponível em: www.senado.gov.br/sf/publicaçoes/anais/ asp/ pq_resultado.asp

ASSIS BRASIL, Joaquim Francisco de. A Aliança Libertadora do Rio Grande do Sul ao País. Pedras Altas, RS: Arquivo Assis Brasil, 1925.

A democracia representativa na república: antoogias Brasil: JoquimFransco de Assis Brasil: introdução, José Antonio Giusti Tavares. Brasília: Conselho Editorial do Senado Federal, 1998. Edição fac-similar.

Anais da Assembléia Constituinte (nov-dez. 1933). Rio de Janeiro: Câmara dos Deputados/ Imprensa Nacional, Arquivo Assis Brasil, 1934. v.2, p.501-514.

BACKES, Ana Luiza. Fundamentos da ordem republicana: repensando o Pacto de Campos Sales. Brasília: Câmara dos Deputados, Coordenação de Publicações, 2006.

BARBOSA, Rui. Excursão Eleitoral. Rio de Janeiro: Ministério da Educação e Cultura, 1967. (Obras Completas de Rui Barbosa, 1909. v.36, t.1) 
.Excursão eleitoral. Rio de Janeiro: Ministério da Educacão e Cultura,1967. (Obras Completas de Rui Barbosa, 1910, v.37, t.1)

- Memória sobre a eleição presidencial. Rio de Janeiro: Ministério da Educacão e Cultura, 1967. (Obras Completas de Rui Barbosa, 1910, v.37, t.2,).

Campanha da Bahia. Rio de Janeiro: Fundação Casa de Rui Barbosa, 1988 (Obras Completas de Rui Barbosa, 1919, v.46, t.3).

BRANT, Mario. O Systema do Código Eleitoral em face do Systema Proporcional da Constituição. Rio de Janeiro: Typographia do Jornal do Commercio, 1935.

CABRAL, João da Rocha. Código Eleitoral da Republica dos Estados Unidos do Brasil. Rio de Janeiro: Livraria Editora Freitas Bastos, 1934.

Sistemas Eleitorais do ponto de vista da representação proporcional das minorias. Rio de Janeiro: Livraria Editora Freitas Bastos, 1929.

COSTA, Cruz. O positivismo na República: notas sobre a história do Positivismo no Brasil. São Paulo: Companhia Editora Nacional, 1956. v.291. (Série: 5a. brasiliana, bi blioteca pedagógica brasileira.).

A Legislação Eleitoral Brasileira: histórico, comentários e sugestões. Rio de Janeiro: Departamento de Imprensa Nacional, 1964.

DÉCADA republicana. 2.ed. rev. e atualizada. Brasília: Editora Universi dade de Brasília, 1986. v.59. (Col eção temas brasileiros)

HOBBES, Thomas. Leviatã. São Paulo: Ed. Abril Cultural 1989 (Coleção os pensadores).

JAUME, Lucien. Hobbes et l'etat représentatif moderne. Paris: Presses Universitaires de France, 1986.

JUNQUEIRA, Celina (Org). A filosofia política positivista. Rio de Janeiro: Pontifícia Universidade Católica: Consel ho Federal de Cultura /Editora Documentário, 1979. v.1.

A filosofia política positivista. Rio de Janeiro Pontifícia Universidade Católica: Consel ho Federal de Cultura /Editora Documentário, 1979. v.2.
LAMOUNIER, Bolívar. Formação de um pensamento político autoritário na Primeira República. Uma interpretação. In: FAUSTO, Bóris (Org.). História geral da civilização brasileira. Rio de Janeiro: Editora Bertrand do Brasil, 1990 t.iii,vii

LESSA, Renato. A invencão republicana: Campos Sales, as bases e a decadência da Primeira República Brasileira. Rio de Janeiro: Topbooks, 1999

LOVE, Joseph. Rio Grande do Sul and brazilian regionalism: 1882-1930. Standford: Stanford University Press, 1971.

MEDEIROS, Borges de. 0 poder moderador na República Presidencial: um ante-projecto da Constituição Brasileira. Recife: Livraria Brandão, 1933.

PAIM, Antonio. O apostolado positivista e a República. Coleção pensamento político republicano. Brasília: Ed. Universi dade de Brasília, 1981. (Sel eção e introdução).

(Org). Plataforma política do positivismo ilustrado. Brasília: Ed. Universidade de Brasília, 1981b. (Coleção pensamento político republicano)

SALES, Campos. Da propaganda à presidência. Brasília: Senado Federal, 1998.

SOUZA, Maria do Carmo Campello. O processo políticopartidário na Primeira República. In: MOTA, Carlos Guiherme. Brasil em perspectiva. São Paulo: Difusão Européia do Livro, 1969.

TORRES, Alberto. 0 problema nacional brasileiro: introdução a um programa de organização nacional. São Paulo, Rio de Janeiro, Recife, Porto Alegre: Companhia Editora Nacional, 1938.

VIANA, Oliveira. O idealismo da Constituição. São Paulo, Rio de Janeiro, Recife, Porto Alegre: Companhia Editora Nacional, 1939. Instituições políticas brasileiras. Rio de Janeiro: J. Olympio, 1955.

Problemas de política objectiva. São Paulo: Nacional, 1930. 


\section{AQUESTÃO DAREPRESENTAÇÃO} POLÍTICA NA PRIMEIRA REPÚBLICA

\section{Cristina Buarque de Hollanda}

$\mathrm{O}$ artigo trata o tema da representação política na Primeira República brasileira (1889-1930) a partir de três importantes matrizes de reflexão sobre a questão: o liberalismo, o positivismo e o realismo. Busca-se rejeitar a narrativa usual das primeiras décadas republicanas, baseada unicamente no diagnóstico de corrupção política, e iluminar outras faces importantes do cenário político da época. A despeito das diferenças significativas entre os modelos interpretativos em evidência, que constituem o cerne do artigo, eles convergem na expectativa de protagonismo do Estado na tarefa de unificação e criação do povo.

PALAVRAS-CHAVE: Primeira República, representação política, liberalismo, positivismo, realismo.

\section{THE QUESTION OF POLITICAL REPRESENTATION IN THE FIRST} BRAZILIAN REPUBLIC

Cristina Buarque de Hollanda

The paper treats the theme of political epresentation intheFirstBrazilian Republic représentation politique, au cours de la 1889-1930) starting from three important Première République brésilienne (1889reflection matrixes on the subject: the 1930), à partir de trois perspectives imliberalism, the positivism and the realism. portantes de réflexion : le libéralisme, One aims to reject the usual narrative of le positivisme et le réalisme. On essaie the first republican decades, based only on de ne pas prendre en considération la the diagnosis of political corruption, and narrative habituelle des premières to illuminate other important faces of the décennies républicaines, basée political scenery at the time. A despeito das uniquement sur le diagnostic de la diferenças significativas entre os modelos corruption politique, et de montrer interpretativos em evidência, que consti- d'autres aspects importants du scénario tuem o cerne do artigo, eles convergem na politique de l'époque. En dépit des expectativa de protagonismo do Estado na différences significatives entre les tarefa de unificação e criação do povo. In modèles interprétatifs mis en évidence, spite of significant differences among the qui constituent le noyau de cet article, interpretative models in evidence, that il existe une convergence qui va dans le

constitute the core of this paper, they con- sens d'une attente, celle de voir l'Etat verge in the expectation of protagonism of devenir le protagoniste de l'unification the State in the creation of the people and et de la formation du peuple. unification task.

Mots-ClÉs: Première République, reKEYworDS: First Republic, political repre- présentation politique, libéralisme, sentation, liberalism, positivism, realism. positivisme, réalisme. 